\title{
Can the histological changes and inflammatory response in meninges caused by spinal block through tattooed skin progress to adhesive arachnoiditis ? An experimental model in Rabbits.
}

\author{
R. SILVA, I. L. Ferraz, R. S. Zuza, C. Camara, V. Dos Santos, E. M. Ganem
} Botucatu Medical School, University of São Paulo State, UNESP, Botucatu, São Paulo, Brazil - DEPARTAMENT OF ANESTHESIOLOGY

\section{Background and Goal of Study}

The intrathecal injection of saline through a needle inserted through tattooed skin was capable of producing histological changes over the meninges of rabbits 6 months after lumbar puncture in a previous research ${ }^{1}$. The purpose of this study is assess if the inflammatory response in meninges caused by spinal block through tattooed skin of rabbits appearing early, if is progressive and if develop to adhesive arachnoiditis

\section{Materials and Methods}

Fourty two young male adult rabbits were divided by lot into 3 groups as follows:

Gl: spinal puncture through tattooed skin and saline injection, captivity for 30 days

GII: spinal puncture through tattooed skin and saline injection, captivity for 360 days

GIII: spinal puncture through non tattooed skin and saline injection, captivity for 30 days.

The subarachnoid space was punctured at S1-S2 under ultrasound guidance with a 22-gauge 21/2 Quincke needle. After the period of captivity all animals were killed by decapitation to avoid cellular death. The lumbosacral spinal cord portion was removed for histological analysis using hematoxylin-eosin stain.

\section{CONCLUSION}

\section{Results and Discussion}

None of the animals for the control group (GIII) shows signs of injuries to meninges. After 30 days of spinal block through tattooed skin, $78,5 \%$ of the animals for $\mathrm{Gl}$ shows signs of perivascular lymphoplasmacyte infiltration in the pia matter and aracnhoid (leptomeninges). And after 360 days, $92,8 \%$ of the animals from Gll showed inflammatory infiltration and areas of adherence in the leptomeninges,changes compatible with arachnoiditis.

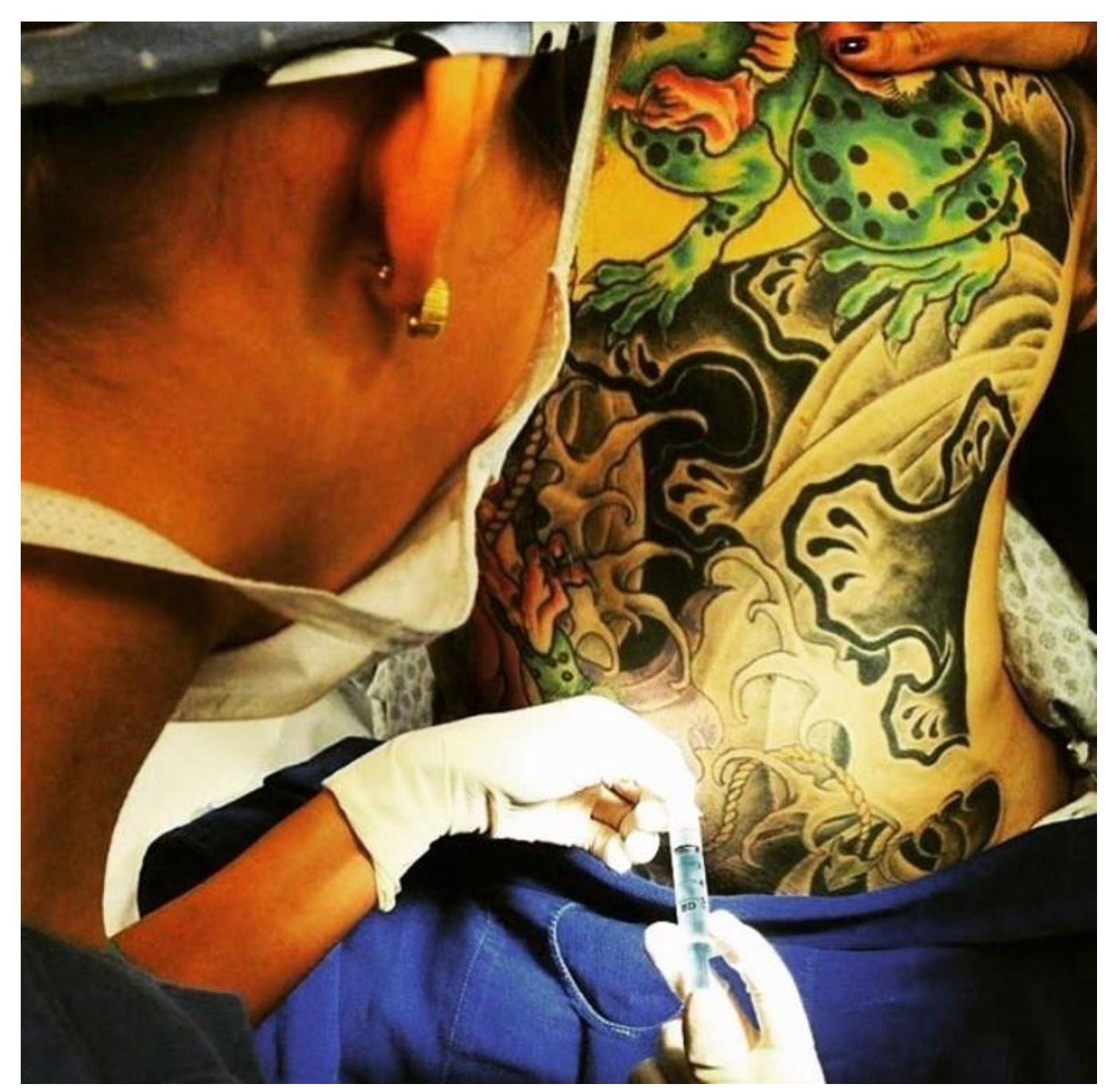

On the basis of the present results, intrathecal injection of saline through a needle inserted through tattooed skin is capable of producing histological changes and inflammation over the meninges of rabbits. Some changes are compatible with ARACHNOIDITIS

1.Does spinal blockade through tattoed skin cause histological changes in nervous tissue and meninges? An experiemtal model in rabbits. Regional Anesthesia and 